\title{
Increase in non-specific bronchial hyperresponsiveness as an early marker of bronchial response to occupational agents during specific inhalation challenges
}

\author{
O Vandenplas, J P Delwiche, J Jamart, R Van de Weyer
}

\begin{abstract}
Background-Specific bronchial reactivity to occupational agents may decline after exposure in the workplace ceases leading to falsely negative specific inhalation challenges. A study was carried out to assess prospectively whether increases in nonspecific bronchial hyperresponsiveness could be useful in detecting the bronchial response to occupational agents during specific inhalation challenges.

Methods - Specific inhalation challenges were performed in 66 subjects with possible occupational asthma due to various agents. After a control day the subjects were challenged with the suspected agent for up to two hours on the first test day. Those subjects who did not show an asthmatic reaction were rechallenged on the next day for 2-3 hours. The provocative concentration of histamine causing a $20 \%$ fall $\left(\mathbf{P C}_{20}\right)$ in the forced expiratory volume in one second $\left(\mathrm{FEV}_{1}\right)$ was assessed at the end of the control day as well as six hours after each challenge that did not cause a $\geq 20 \%$ fall in $\mathrm{FEV}_{1}$. The subjects who had a significant ( $\geq 3 \cdot 1$-fold) reduction in $\mathbf{P C}_{20}$ value at the end of the second challenge day were requested to perform additional specific inhalation challenges.
\end{abstract}

Results - The first test day elicited an asthmatic reaction in 25 subjects. Of the other 41 subjects five $(12 \%, 95 \%$ confidence interval (CI) $4 \%$ to $26 \%$ ) exhibited a $\geq 3 \cdot 1$ fold fall in the $\mathbf{P C}_{20}$ value after the inhalation challenge and developed an asthmatic reaction during the second $(n=3)$ or third $(n=2)$ challenge exposure. The offending agents included persulphate $(n=$ $1)$, wood dust $(n=2)$, isocyanate $(n=1)$, or amoxycillin $(n=1)$. These five subjects had left their workplace for a longer period (mean (SD) 21 (14) months) than those who reacted after the first specific inhalation challenge (8 (11) months).

Conclusions - The increase in non-specific bronchial hyperresponsiveness after a specific inhalation challenge can be an early and sensitive marker of bronchial response to occupational agents, especially in subjects removed from workplace exposure for a long time. Non-specific bronchial hyperresponsiveness should be systematically assessed after specific in- halation challenges in the absence of changes in airway calibre.

(Thorax 1996;51:472-478)

Keywords: occupational disease, asthma, bronchial provocation tests.

Occupational asthma is increasingly recognised as the most common cause of work related respiratory disease in industrialised countries. Affected workers should be completely and definitively removed from exposure to the causative agent in order to prevent further deterioration of asthma and to minimise long term sequelae. ${ }^{2}$ The medical and socioeconomic consequences of occupational asthma ${ }^{34}$ make reliable diagnosis important. Monitoring of peak expiratory flow rates (PEFR) at work and away from work is useful in assessing the work-relatedness of asthma, ${ }^{5-7}$ although the procedure cannot be carried out when subjects have left or lost their job.

Although specific inhalation challenges are still regarded as the gold standard method for confirming occupational asthma, ${ }^{5-7}$ a negative result does not absolutely rule out the diagnosis of occupational asthma. Specific bronchial reactivity to occupational agents may decline after removal from exposure ${ }^{8-11}$ and may reappear when the subjects are re-exposed to the offending agent. ${ }^{89}$ Similar changes have been documented with non-specific bronchial hyperresponsiveness. ${ }^{1213}$ An isolated observation of a subject with occupational asthma due to Western red cedar suggested that an increase in bronchial hyperresponsiveness may precede the development of an asthmatic reaction. ${ }^{14}$ Challenge exposure to red cedar carried out three months after the subject had left his work caused an increase in bronchial hyperresponsiveness in the absence of significant changes in airway calibre. An asthmatic reaction was elicited only by challenging the subject for longer periods on the following days.

The aim of this study was to evaluate prospectively whether increases in non-specific bronchial hyperresponsiveness could be useful in detecting the bronchial response to occupational agents during specific inhalation challenges. Non-specific bronchial hyperresponsiveness to histamine was assessed on a control day and after each challenge that did not elicit significant airways obstruction. In 
the absence of an asthmatic reaction challenge exposure to the suspected occupational agent was repeated at least once on the next day before excluding occupational asthma.

\section{Methods \\ SUBJECTS}

Sixty six consecutive subjects investigated for possible occupational asthma over a two year period were included in the study. They were referred for specific inhalation challenge tests either by their attending physician $(n=14)$ or by the Belgian Workers' Compensation Board $(n=52)$. These tests were carried out when other diagnostic tests did not provide conclusive results. The subjects completed a detailed medical and occupational questionnaire and all reported work related respiratory symptoms consistent with occupational asthma caused by various agents (table 2 ). They were skin prick tested with common inhaled allergens and with occupational agents such as flour and latex when available. Atopy was defined by the presence of a positive skin reaction to at least one of the common allergens. The procedures used in the study were approved by the local ethics committee.

\section{STUDY DESIGN}

The subjects underwent specific inhalation challenges and assessment of non-specific bronchial hyperresponsiveness according to a standardised protocol. On the control day, subjects were exposed to a control product - for example, lactose powder, pine dust, diluent usually mixed with the tested compound for 30-60 minutes and spirometric parameters were monitored for six hours to ensure that fluctuations of forced expiratory volume in one second $\left(\mathrm{FEV}_{1}\right)$ were $\leq 10 \%$. The baseline level of non-specific bronchial hyperresponsiveness to histamine was determined at the end of the control day. On the next day (first test day) the subjects were challenged with the suspected occupational agent. The duration of exposure was progressively increased (one, four, 15, 40, 60 minutes) until a $\geq 20 \%$ fall in $\mathrm{FEV}_{1}$ occurred or a cumulative exposure of two hours was completed. Non-specific bronchial hyperresponsiveness was reassessed six hours after the end of the exposure in the absence of significant changes in $\mathrm{FEV}_{1}$. Those subjects who did not show a significant $(\geq 20 \%)$ fall in $\mathrm{FEV}_{1}$ during the first test day underwent a repeated challenge test for two hours on the next day (second test day). When changes in $\mathrm{FEV}_{1}$ of $\geq 10 \%$ but $<20 \%$ were observed after two hours the exposure was prolonged up to three hours. FEV ${ }_{1}$ and non-specific bronchial hyperresponsiveness following the challenge were monitored in the same way as for the first test day. The subjects who had a significant ( $\geq 3 \cdot 1$-fold) decrease in non-specific bronchial hyperresponsiveness at the end of the second test day (compared with the control day value) were asked to perform additional inhalation challenge tests.
SPECIFIC INHALATION CHALLENGES

Specific inhalation challenges were performed according to recent guidelines. ${ }^{1516}$ Anti-asthmatic medications were withheld for the intervals recommended. Treatment with inhaled and oral corticosteroids was continued but the total daily dose was given in the evening of each day (at least 10 hours before the next test) to maintain asthma stability throughout the challenge tests. $^{16} \mathrm{~A}$ short acting inhaled bronchodilator (salbutamol, $200 \mu \mathrm{g}$ ) was given on demand after $56 \%$ of assessments of bronchial hyperresponsiveness following the challenge tests had been made.

Spirometric values were obtained before exposure and were reassessed every 15 minutes for the first hour, every 30 minutes for the second hour, and then hourly for at least six hours after the end of exposure. The PEFR was monitored hourly during the day and evening as well as at night whenever required. Specific inhalation challenges were considered positive when a sustained fall of $\geq 20 \%$ in $\mathrm{FEV}_{1}$ was recorded on two consecutive assessments. ${ }^{1516}$ The pattern of bronchial responses was characterised as immediate, late, dual (immediate followed by a late component), or atypical according to previously described criteria. ${ }^{1718}$ Subjects with negative challenge tests were requested to record their PEFR every two hours for at least two weeks at work.

Specific inhalation challenges were carried out in $5 \mathrm{~m}^{3}$ challenge rooms equipped with an exhaust ventilation system and a small fan to ensure air mixing. On active test day(s) the subjects were exposed to the occupational agent suspected of being the cause of work related asthma, based on their clinical history and inspection of the workplace by Workers' Compensation Board hygienists. Challenge exposures to occupational agents were produced in different ways depending on the nature and the physical state of the agent encountered at the workplace (dust, aerosol, vapour, or fume). Agents in powder form - for example, flour, wood dusts, antibiotics, persulphate salts were poured from one tray to another as proposed by Pepys et al. ${ }^{17}$ Isocyanates were generated by evaporation at ambient temperature (toluene diisocyanate), nebulisation (prepolymers of hexamethylene diisocyanate), or heating (diphenylmethane diisocyanate). ${ }^{1619}$ Isocyanate concentrations were continuously monitored using an MDA 7100 tape monitor (MDA Scientific Inc, Glenview, Illinois, USA) and kept below the threshold limit value of $20 \mathrm{ppb}$. Subjects with suspected latex induced asthma were challenged by exposure to airborne natural rubber latex from handling latex gloves, as previously described. ${ }^{20}$ Specific inhalation challenges with other agents were performed in order to reproduce the workplace exposure as closely as possible.

\section{ASSESSMENT OF NON-SPECIFIC BRONCHIAL} HYPERRESPONSIVENESS

Non-specific bronchial hyperresponsiveness was assessed using the standardised procedure described by Cockcroft et al. ${ }^{21}$ Doubling con- 
Table 1 Clinical and functional characteristics of the subjects

\begin{tabular}{|c|c|c|c|}
\hline \multirow[t]{2}{*}{ Characteristics } & \multicolumn{2}{|c|}{ Positive inhalation challenge } & \multirow{2}{*}{$\begin{array}{l}\text { Negative inhalation } \\
\text { challenge } \\
(n=36)\end{array}$} \\
\hline & $\begin{array}{l}\text { First test day } \\
(n=25)\end{array}$ & $\begin{array}{l}\text { Subsequent test day(s) } \\
(n=5)\end{array}$ & \\
\hline $\mathrm{M}: \mathrm{F}$ & $17 / 8$ & $4 / 1$ & $23 / 13$ \\
\hline Age (years) & $37(10)$ & $38(11)$ & $42(10)$ \\
\hline \multicolumn{4}{|l|}{ Smoking habits } \\
\hline Non-smoker, no. (\%) & $16(64)$ & $2(40)$ & $19(53)$ \\
\hline Ex-smoker, no. (\%) & $6(24)$ & $2(40)$ & $4(11)$ \\
\hline Current smoker, no. (\%) & $3(12)$ & $1(20)$ & $13(36)$ \\
\hline Atopy, no. (\%) & $18(72)$ & $3(60)$ & $17(47)$ \\
\hline \multicolumn{4}{|l|}{ Referral } \\
\hline Attending physician, no. (\%) & $6(24)$ & 0 & $8(22)$ \\
\hline Workers' Compensation Board, no. (\%) & $19(76)$ & $5(100)$ & $28(78)$ \\
\hline Mean (SD) duration of exposure (years) & $15(11)$ & $14(8)$ & $16(11)$ \\
\hline Mean (SD) duration of symptoms at work (years) & $5 \cdot 4(7 \cdot 4)$ & $2 \cdot 5(0 \cdot 8)$ & $4 \cdot 7(4 \cdot 6)$ \\
\hline Mean (SD) last workplace exposure (months) & $8(11)$ & $21(14)^{*}$ & $15(20)$ \\
\hline \multicolumn{4}{|l|}{ Treatment at time of inhalation challenge } \\
\hline Inhaled steroid, no. (\%) & $8(32)$ & $1(20)$ & $14(39)$ \\
\hline Inhaled + oral steroid, no. (\%) & $3(12)$ & 0 & $2(5)$ \\
\hline \multicolumn{4}{|l|}{$\mathrm{FEV}_{1}$} \\
\hline Mean (SD) \% pred & $95(17)$ & $100(8)$ & $92(13)$ \\
\hline No. $<80 \%$ pred $(\%)$ & $4(16)$ & 0 & $6(17)$ \\
\hline \multicolumn{4}{|l|}{$\mathrm{FEV}_{1} / \mathrm{FVC}$} \\
\hline Mean (SD) \% pred & $92(9)$ & $93(1)$ & $90(9)$ \\
\hline No. $<80 \%$ pred & $3(12)$ & 0 & $7(19)$ \\
\hline \multicolumn{4}{|l|}{ Baseline $\mathrm{PC}_{20}(\mathrm{mg} / \mathrm{ml})$} \\
\hline$<2$ & $20(80)$ & $1(20) \dagger$ & $29(81)$ \\
\hline $2-8$ & $2(8)$ & $3(60)$ & $4(11)$ \\
\hline$>8$ & $3(12)$ & $1(20)$ & $3(8)$ \\
\hline
\end{tabular}

$\mathrm{FEV}_{1}=$ forced expiratory volume in one second $\mathrm{FVC}=$ forced vital capacity; $\mathrm{PC}_{20}=$ concentration provoking a $20 \%$ fall in $\mathrm{FEV}$. ${ }^{*} \mathrm{p}<0.05$ versus subjects who showed a positive inhalation challenge on the first test day; $\uparrow \mathrm{p}<0.05$ versus subjects who showed a positive inhalation challenge on the first test day and those with a negative test result.

centrations of histamine from 0.03 to $16 \mathrm{mg} /$ $\mathrm{ml}$ were delivered with a Wright's nebuliser (output $=0.14 \mathrm{ml} / \mathrm{min}$ ) at tidal breathing for two minutes. The provocative concentration of histamine causing a $20 \%$ fall in $\mathrm{FEV}_{1}\left(\mathrm{PC}_{20}\right)$ was interpolated from the individual dose response curve. Histamine $\mathrm{PC}_{20}$ was assessed at the end of the control day (baseline value) and reassessed 6-7 hours after each challenge exposure that did not induce significant bronchial reaction, when $\mathrm{FEV}_{1}$ was within $\pm 10 \%$ of the corresponding control day value.

The changes in histamine $\mathrm{PC}_{20}$ values were expressed as the ratio of the $\mathrm{PC}_{20}$ on the control day to the $\mathrm{PC}_{20}$ following challenge. Non-specific bronchial hyperresponsiveness was con-

Table 2 Results of specific inhalation challenge tests

\begin{tabular}{|c|c|c|c|}
\hline & \multicolumn{2}{|c|}{ Positive inhalation challenge } & \multirow{2}{*}{$\begin{array}{l}\text { Negative } \\
\text { inhalation } \\
\text { challenge } \\
(n=36)\end{array}$} \\
\hline & $\begin{array}{l}\text { First test } \\
\text { day } \\
(n=25)\end{array}$ & $\begin{array}{l}\text { Subsequent test } \\
\text { day }(s) \\
(n=5)\end{array}$ & \\
\hline \multicolumn{4}{|l|}{ Occupational agents } \\
\hline Isocyanates & 5 & 1 & 9 \\
\hline Flour & 5 & $\ldots$ & 5 \\
\hline Latex & 7 & - & 3 \\
\hline Woods & 3 & 2 & 3 \\
\hline Antibiotics & - & 1 & 4 \\
\hline Persulphate salts & 1 & 1 & 2 \\
\hline Aldehyde biocides & - & - & 4 \\
\hline Welding & 1 & - & 2 \\
\hline Reactive dye & 1 & - & - \\
\hline Nickel sulphate & 1 & - & - \\
\hline Herbal tea & 1 & - & - \\
\hline Epoxy paints & - & - & 2 \\
\hline Styrene & - & - & 2 \\
\hline Geometric mean baseline $\mathrm{PC}_{20}(\mathrm{mg} / \mathrm{ml})$ & $0.5(6 \cdot 3)$ & $3 \cdot 1(5 \cdot 6)^{*}$ & $0 \cdot 7(4 \cdot 0)$ \\
\hline \multicolumn{4}{|l|}{ Geometric mean post-challenge $\mathrm{PC}_{20}(\mathrm{mg} / \mathrm{ml})$} \\
\hline First test day & ND & $0 \cdot 4(5 \cdot 5)$ & $0 \cdot 7(4 \cdot 2)$ \\
\hline Second test day & ND & $0 \cdot 4(2 \cdot 1)$ & $0.9(4 \cdot 7)$ \\
\hline Mean (SD) maximal fall in $\mathrm{FEV}_{1}$ (\% baseline) & $32(8)$ & $22(12)$ & \\
\hline \multicolumn{4}{|l|}{$\begin{array}{l}\text { Pattern of asthmatic reaction } \\
\text { Pand }\end{array}$} \\
\hline Immediate & 14 & 2 & \\
\hline Late & 4 & $(1) \dagger$ & \\
\hline Dual & 3 & 0 & \\
\hline Atypical & 4 & 2 & \\
\hline
\end{tabular}

$\mathrm{FEV}_{1}=$ forced expiratory volume in one second; $\mathrm{PC}_{20}=$ concentration provoking a $20 \%$ fall in

$\mathrm{FEV}_{1}$.
$* \mathrm{p}<0.05$ versus subjects who showed a positive inhalation challenge on the first day and those with negative challenge test; $†$ maximal fall in $\mathrm{FEV}$, of $16 \%$ from prechallenge value. sidered to be significantly increased following inhalation challenge when this ratio was $\geq 3 \cdot 1$ - that is, when a $\geq 3 \cdot 1$-fold reduction in $\mathrm{PC}_{20}$ value was recorded after inhalation challenge - as this figure represents the mean $+2 S D$ of the ratio between two $\mathrm{PC}_{20}$ values determined in 18 clinically stable asthmatic subjects assessed at the same time of day on two occasions separated by a $2-15$ day interval.

\section{ANALYSIS OF RESULTS}

Histamine $\mathrm{PC}_{20}$ values were expressed as the geometric mean (SD) and compared using paired or unpaired Student's $t$ tests after logarithmic transformation. Other numerical variables were compared by the Wilcoxon rank sum test, and $\chi^{2}$ or Fisher's exact tests were used for comparing categorical variables. All tests were two tailed. A $p$ value of $\leq 0.05$ was considered significant.

\section{Results}

The clinical and baseline functional features of the subjects are summarised in table 1 , and the occupational agents and results of specific inhalation challenges are presented in table 2 . The first challenge exposure to occupational agents elicited a significant $(\geq 20 \%)$ fall in $\mathrm{FEV}_{1}$ in $25(38 \%)$ of the 66 subjects, including immediate $(n=14)$, dual $(n=3)$, late $(n=4)$, and atypical $(n=4)$ asthmatic reactions. The mean (SD) duration of challenge exposure that induced an asthmatic response was 70 (59) minutes (range 2-180).

Of the 41 subjects who did not show bronchial obstruction during the first test day six exhibited a significant ( $\geq 3 \cdot 1$-fold) fall in histamine $\mathrm{PC}_{20}$ six hours after exposure compared with the control day value. Five of these six subjects developed an asthmatic reaction on subsequent challenge testing, whereas the fall 

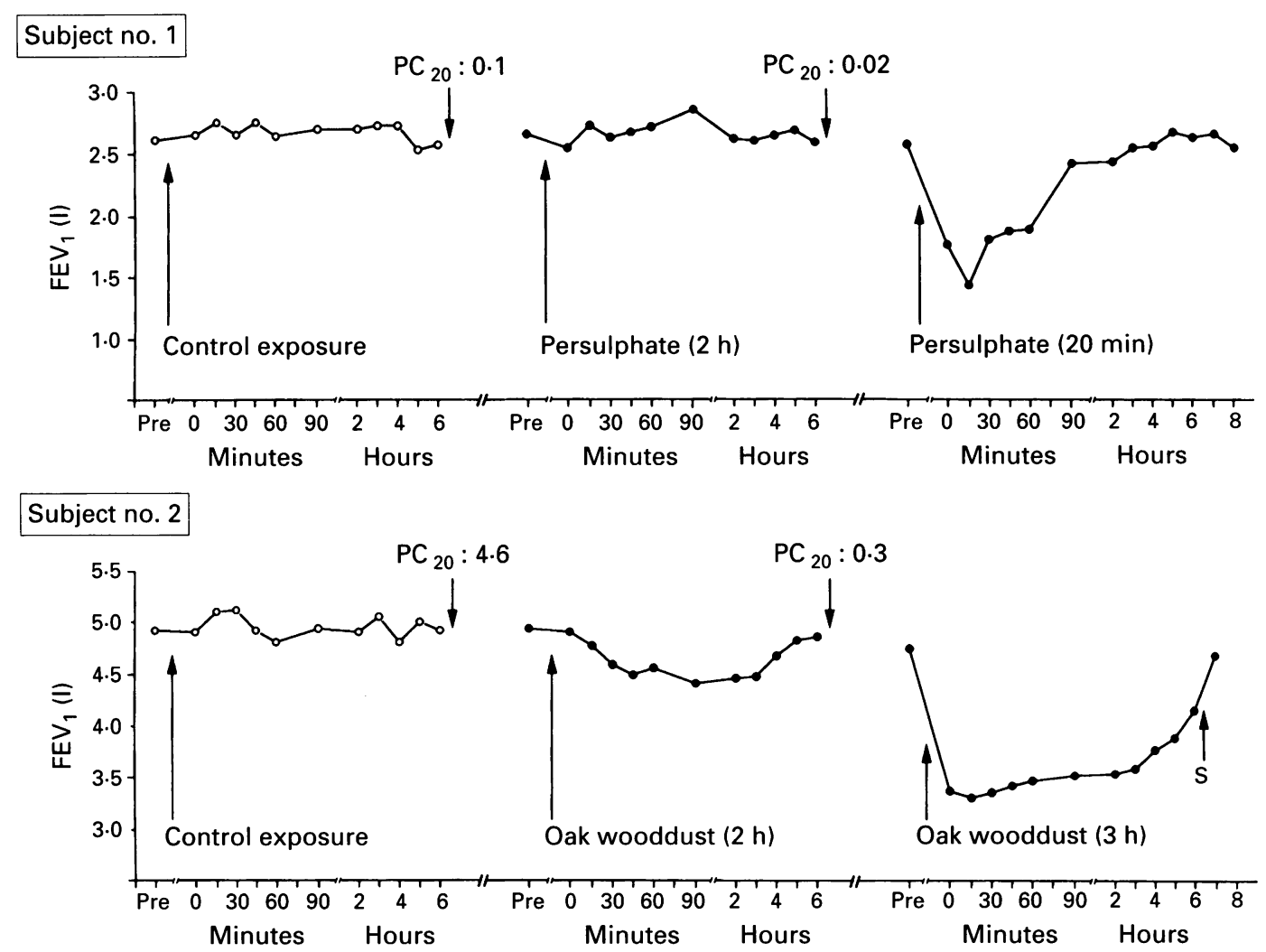

Figure 1 Results of specific inhalation challenges in subjects nos 1 and 2 showing the changes in forced expiratory volume in one second (FEV $)$ and the concentration of histamine provoking a $20 \%$ fall in FEV $(\mathrm{mg} / \mathrm{ml})\left(P C_{20}\right)$ after exposure to a control substance $(\mathrm{O})$ and suspected allergens (O, persulphate for subject 1 and oak wood dust for subject 2). $S=$ inhaled $\beta_{2}$ adrenergic agent (salbutamol, $200 \mu \mathrm{g}$ ).

in $\mathrm{PC}_{20}$ was not confirmed after the second test day in the remaining subject. The results of the challenge tests in these five subjects are presented in figs 1 and 2 . The responsible agents included persulphate salts, oak wood dust, black meranti wood dust, hexamethylene diisocyanate, and amoxycillin. The reductions in histamine $\mathrm{PC}_{20}$ (control day $\mathrm{PC}_{20}$ :first test day $\mathrm{PC}_{20}$ ) were $4 \cdot 4,14 \cdot 7,22 \cdot 7,6 \cdot 2$, and $3 \cdot 1$. Two of the five subjects (nos 1 and 2) developed an asthmatic reaction after the second test day (fig 1). Subject no. 3 had a maximal fall in $\mathrm{FEV}_{1}$ of $16 \%$ seven hours after the second challenge exposure to hexamethylene diisocyanate (fig 2) without later changes in PEFR. He refused to perform additional specific inhalation challenge tests in the laboratory and could not be re-exposed to his workplace. His histamine $\mathrm{PC}_{20}$ value assessed three weeks after the inhalation challenges was markedly increased $(8.0 \mathrm{mg} / \mathrm{ml})$ compared with the value recorded after the first test day $(0.3 \mathrm{mg} / \mathrm{ml})$, and had returned toward the control day value $(6.6 \mathrm{mg} / \mathrm{ml})$. Despite the absence of $\geq 20 \%$ changes in $\mathrm{FEV}_{1}$, this subject was considered to have a positive inhalation challenge since serial assessments of histamine $\mathrm{PC}_{20}$ suggested that the observed changes in bronchial hyperresponsiveness were actually related to exposure to hexamethylene diisocyanate. Subject no. 4 showed a further decline in histamine $\mathrm{PC}_{20}$ after the second test day (control day: second test day $\mathrm{PC}_{20}$ ratio of $20 \cdot 8$ ) and developed an immediate asthmatic reaction during the third test day (fig 2). Subject no. 5 showed a $3 \cdot 1$-fold decrease in histamine $\mathrm{PC}_{20}$ after the first challenge exposure to amoxycillin, while the fall in $\mathrm{PC}_{20}$ reached a 5.1-fold difference after the second test day (fig 2). The subject was sent back to his workplace in an antibiotic manufacturing plant where he experienced asthma and deterioration in PEFR after five days at work. Histamine $\mathrm{PC}_{20}$ at the end of the fifth workshift was 21.4 times lower than the control day value. Challenge exposure to amoxycillin for two hours on the next day (third test day) in the laboratory caused a significant bronchial reaction.

Although their small number precluded reliable statistical comparison, the five subjects who developed an asthmatic reaction after repeated specific inhalation challenge tests had been away from their workplaces for longer (mean (SD) 21 (14) months) than those with positive results on the first test day ( 8 (11) months, $\mathrm{p}<0.05)$. These five subjects also had a higher baseline mean $\mathrm{PC}_{20}$ value $(3.1 \mathrm{mg}$ / $\mathrm{ml})$ than both those with a positive inhalation challenge result on the first test day $(0.5 \mathrm{mg} /$ $\mathrm{ml})$ and those with a negative result $(0.7 \mathrm{mg} /$ $\mathrm{ml} ; \mathrm{p}<0.05)$. Only one of them had a baseline $\mathrm{PC}_{20}$ of $<2 \mathrm{mg} / \mathrm{ml}$, while $80 \%$ of the subjects in the other two groups had such a value $(p<0.05$, Fisher's test). The increases in non-specific bronchial hyperresponsiveness following inhalation challenge appeared to occur independently of changes in airway calibre. The baseline $\mathrm{FEV}_{1}$ at the time of post-challenge assessment of histamine $\mathrm{PC}_{20}$ was $-0.9(4 \cdot 0) \%$ (range $-7 \cdot 5 \%$ to $+6 \cdot 0 \%$ ) of the corresponding value on the control day. 

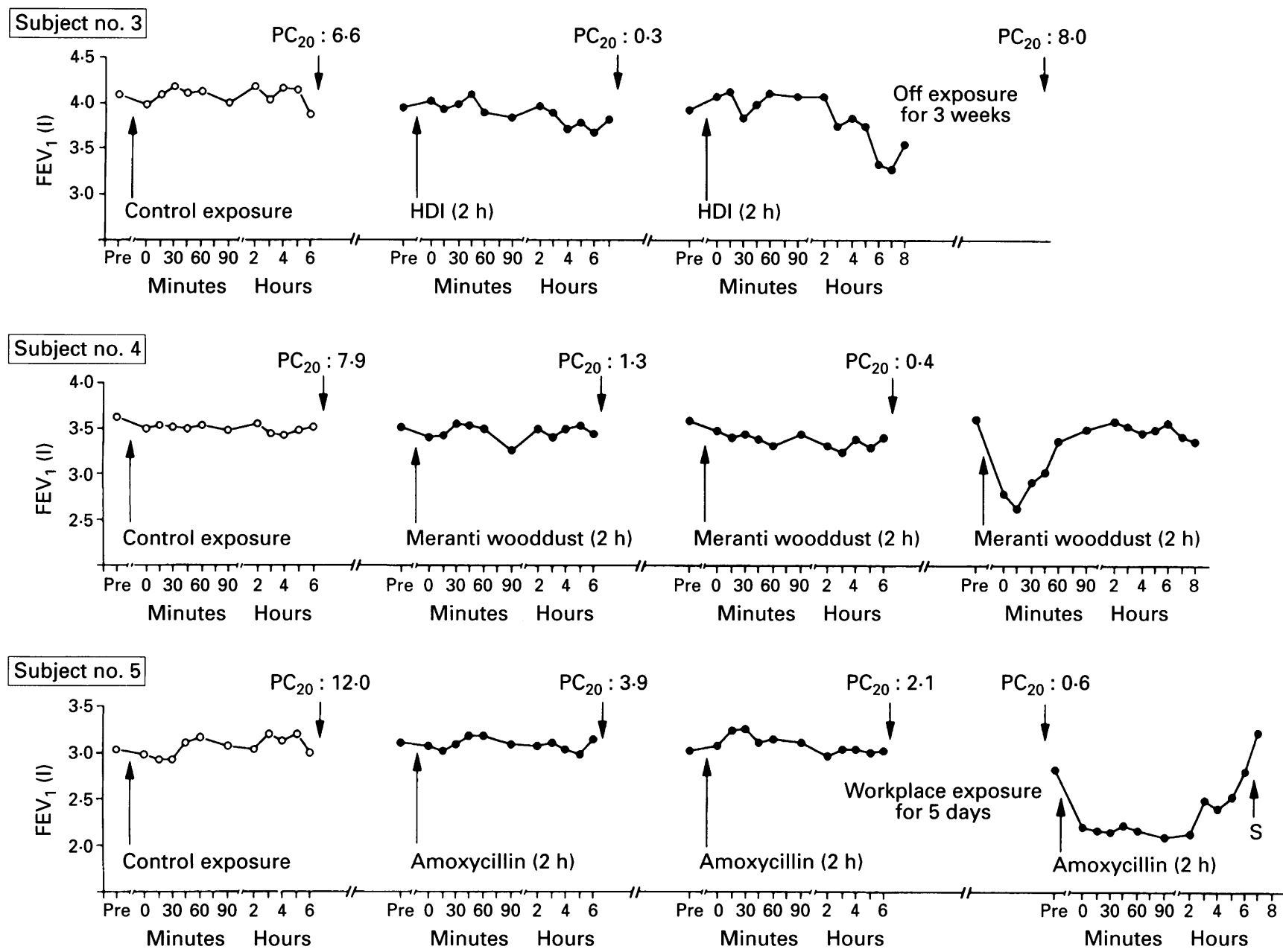

Figure 2 Results of specific inhalation challenges in subjects 3, 4, and 5 showing the changes in forced expiratory volume in one second (FEV $V_{1}$ and concentration of histamine provoking a 20\% fall in $F E V_{1}(\mathrm{mg} / \mathrm{ml})\left(P C_{20}\right)$ after exposure to a control substance (O) and suspected allergens (O, hexamethylene diisocyanate (HDI) for subject 3 , black meranti wood dust for subject 4 , and amoxycillin for subject 5 ). $S=$ inhaled $\beta_{2}$ adrenergic agent (salbutamol, $200 \mu \mathrm{g}$ ).

In the remaining subjects with negative inhalation challenges the mean histamine $\mathrm{PC}_{20}$ values remained unchanged after the first $(0.7 \mathrm{mg} / \mathrm{ml})$ and second $(0.9 \mathrm{mg} / \mathrm{ml})$ test days compared with the control day $(0.7 \mathrm{mg} / \mathrm{ml})$. Unfortunately, recording of PEFR during workplace exposure could not be systematically obtained for the subjects with negative challenge tests. Most of them had resigned their jobs and were not allowed to be re-exposed at work or they were not interested in performing the procedure. The absence of occupational asthma could be further confirmed in five subjects by monitoring of PEFR.

\section{Discussion}

Five of 41 (12\%, $95 \%$ CI $4 \%$ to $26 \%)$ subjects with negative specific inhalation challenge tests on the first test day developed an asthmatic reaction on repeated challenge exposure to the suspected occupational agent. In all five subjects a significant increase in non-specific bronchial hyperresponsiveness was recorded before the occurrence of the asthmatic reaction. Airways obstruction was elicited during the second test day in three subjects and during the third test day in two subjects. This prospective study confirms that an increase in non-specific bron- chial hyperresponsiveness may precede the development of an asthmatic response in subjects who have been removed from workplace exposure of a suspected allergen for an extended period. ${ }^{14}$ Increases in non-specific bronchial hyperresponsiveness can be more sensitive than changes in spirometric parameters in assessing the bronchial response to occupational agents. As recommended, ${ }^{1516}$ specific inhalation challenges were considered positive when a $\geq 20 \%$ fall in $\mathrm{FEV}_{1}$ was recorded, provided that changes of $>10 \%$ did not occur on the control day. Statistical approaches have recently been proposed to increase the sensitivity of detecting late asthmatic reactions by comparing the decrements in $\mathrm{FEV}_{1}$ on challenge days to that observed on control days. ${ }^{22}$ However, these methods have major practical limitations. They require serial measurements of spirometric parameters on at least three control days to obtain an adequate estimate of the spontaneous variability in $\mathrm{FEV}_{1}$, which makes the tests unacceptably long.

It has been pointed out that a long interval between exposure to a suspected allergen and specific inhalation challenge testing may lead to false negative results ${ }^{5-7}$ because some subjects with occupational asthma lose specific bronchial reactivity to the causal agent after avoid- 
ance of exposure..$^{8-11}$ The outcome of specific bronchial reactivity to occupational agents after cessation of exposure has not been extensively investigated for obvious ethical reasons. It is therefore not known how long a subject should be exposed to an occupational agent before a specific inhalation challenge test can be considered negative. This study shows that prolonged challenge exposure to the offending agent may be required to provoke the reappearance of a specific bronchial response in subjects who have not been exposed for a prolonged period. Our study may, however, overestimate the proportion of subjects in whom repeated challenges are required to elicit an asthmatic reaction. The interval of time between the last exposure in the workplace and inhalation challenge was rather prolonged, with $55 \%$ of subjects being challenged more than three months after they had left work. In previous studies from which this information is available, most subjects were assessed within three months. ${ }^{23-25}$ It is interesting that the five subjects who had a positive inhalation challenge test result after repeated challenges had been away from the workplace for a significantly longer time than the subjects who had positive test results after the first test day, although a threshold interval could not be reliably delineated.

Our data indicate that an increase in nonspecific bronchial hyperresponsiveness represents an early and reliable marker of subsequent bronchial response to occupational agents. The possibility that some of the subjects who showed no changes in $\mathrm{FEV}_{1}$ nor in $\mathrm{PC}_{20}$ during the two test days would have developed an asthmatic reaction after further challenge exposures seems unlikely. The proportion of subjects with positive specific inhalation challenge tests ( 30 of $66,45 \%)$ is similar to the figures $(41-57 \%)$ reported in previous studies, ${ }^{23-28}$ including one study where monitoring of PEFR was combined with inhalation challenge tests. ${ }^{25}$ Furthermore, the cumulative duration of exposure to occupational agents in our protocol is longer than that used in other centres. $^{2426}$ The absence of occupational asthma could be further excluded by monitoring of PEFR at work in the five subjects for whom this procedure could be carried out.

One possible criticism of our protocol is that isolated late reactions could have occurred had histamine challenges not been performed six hours after exposure. However, our subjects were challenged for at least two hours on two consecutive days before excluding occupational asthma. With such prolonged exposures late reactions are likely to develop within six hours after the end of exposure. ${ }^{18}$ Studies have shown that high doses of occupational agents and common allergens are associated with the development of an immediate response or with an earlier occurrence of the late response. ${ }^{29} 30$ Furthermore, none of the subjects showed significant changes in PEFR in the evening and at night following negative specific inhalation challenge tests.

The rationale for assessing histamine $\mathrm{PC}_{20}$ six hours after the end of challenge exposure to occupational agents was based on current knowledge of the changes in non-specific bronchial hyperresponsiveness after allergen challenges, as well as on pragmatic considerations. Enhancement of non-specific bronchial hyperresponsiveness has been described in relation to late asthmatic reactions induced by occupational agents ${ }^{31}$ and common aeroallergens. ${ }^{32}$ In these studies non-specific bronchial hyperresponsiveness increased 7-8 hours after allergen exposure and progressively returned to baseline level within a period of one day to four weeks. ${ }^{31}$ An increase in non-specific bronchial hyperresponsiveness may precede the development of the late component of dual reactions occurring 1-3 hours after resolution of the immediate response. ${ }^{293}$ Changes in nonspecific bronchial hyperresponsiveness have also been observed in a substantial proportion of subjects within 12 hours after isolated immediate reactions to various occupational agents. ${ }^{34}$ By contrast, the time course of changes in non-specific bronchial hyperresponsiveness after challenges that do not elicit an asthmatic reaction is unknown. The optimal timing for assessing post-challenge non-specific bronchial hyperresponsiveness therefore warrants further investigation. From a practical point of view, measurement of histamine $\mathrm{PC}_{20}$ at six hours after exposure makes it possible to avoid too long a stay in the laboratory for the subjects while permitting us to rechallenge them the next morning when indicated.

We conclude that changes in non-specific bronchial hyperresponsiveness represent early and sensitive markers of a bronchial response to occupational agents. Non-specific bronchial hyperresponsiveness should be systematically assessed after specific inhalation challenges. When monitoring of spirometric parameters is negative, a significant increase in postchallenge non-specific bronchial hyperresponsiveness means that further challenge exposure in the laboratory and/or in the workplace is needed before excluding the diagnosis of occupational asthma. Alternatively, reproducible increases in non-specific bronchial hyperresponsiveness could be considered as reflecting a significant bronchial response when changes in spirometric values do not fulfil the recommended criteria. This procedure should enhance the degree of confidence with which occupational asthma can be ruled out after specific inhalation challenge testing.

The authors wish to thank Mrs Lori Schubert for reviewing the manuscript.

1 Meredith SK, Taylor VM, McDonald JC. Occupational respiratory disease in the United Kingdom 1989: a repor to the British Thoracic Society and the Society of Occupational Medicine by the SWORD project group. $\mathrm{Br} f$ Ind Med 1991;48:292-8.

2 Chan-Yeung M, Malo JL. Natural history of occupational asthma. In: Bernstein IL, Chan-Yeung M, Malo JL, Bernstein DI, eds. Asthma in the workplace. New York: Marcel Dekker, 1993:299-322.

3 Venables KM, Davison AG, Newman Taylor AJ. Consequences of occupational asthma. Respir Med 1989;83: 437-40.

4 Gannon PFG, Weir DC, Robertson AS, Burge PS. Health, employment, and financial outcomes in workers with occupational asthma. Br f Ind Med 1993;50:491-6.

5 Burge PS. Diagnosis of occupational asthma. Clin Allengy

6 Chan-Yeung M. Occupational asthma. Chest 1990;98:148$61 \mathrm{~S}$. 
7 Cartier A. Definition and diagnosis of occupational asthma. Eur Respir f 1994;7:153-60.

8 Cartier A, Malo J-L, Forest F, Lafrance M, Pineau L St-Aubin J-J, et al. Occupational asthma in snow crabprocessing workers. $\mathcal{F}$ Allergy Clin Immunol 1984;74:261-9.

9 Banks DE, Rando RJ. Recurrent asthma induced by toluene diisocyanate. Thorax 1988;43:660-2.

10 Mapp CE, Corona PC, De Marzo N, Fabbri L. Persistent asthma due to isocyanates. A follow-up study of subjects with occupational asthma due to toluene diisocyanate. $\mathrm{Am}$ Rev Respir Dis 1988;137:1326-9.

11 Paggiaro PL, Vagaggini B, Dente FL, Bacci E, Bancalar $\mathrm{L}$, Carrara $\mathrm{M}$, et al. Bronchial hyperresponsiveness and toluene diisocyanate. Long-term change in sensitized asthmatic subjects. Chest 1993;103:1123-8.

12 Hargreave FE, Ramsdale EH, Pugsley SO. Occupational asthma without bronchial hyperresponsiveness. Am Rev Respir Dis 1984;130:513-5.

13 Mapp CE, Dal Vecchio L, Boschetto P, De Marzo N, Fabbri LM. Toluene diisocyanate-induced asthma without airwa hyperresponsiveness. Eur f Respir Dis 1986;68:89-95.

14 Cartier A, L'Archevêque J, Malo JL. Exposure to a sensitizing occupational agent can cause a long-lasting increase in bronchial responsiveness to histamine in the absence of significant changes in airway caliber. $f$ Allergy Clin of significant changes in

15 Cartier A, Bernstein IL, Burge PS, Cohn JR, Fabbri LM Hargreave FE, et al. Guidelines for bronchoprovocation on the investigation of occupational asthma. Report of the subcommittee on bronchoprovocation for occupational asthma. 7 Allergy Clin Immunol 1989;84:823-9.

16 Sterk PJ, Fabbri LM, Quanjer PH, Cockcroft DW, O'Byrne PM, Anderson SD, et al. Airway responsiveness. Standardized challenge testing with pharmacological, physical and sensitizing stimuli in adults. Official statement of the European Respiratory Society. Eur Respir f 1993;6(Supp 16):53-83.

17 Pepys J, Hutchcroft BJ. Bronchial provocation tests in etiologic diagnosis and analysis of asthma. Am Rev Respir Dis 1975;112:829-59.

18 Perrin B, Cartier A, Ghezzo H, Grammer L, Harris K, Chan $\mathrm{H}$, et al. Reassessment of the temporal pattern of bronchial obstruction after exposure to occupationa sensitizing agents. $\mathcal{F}$ Allergy Clin Immunol 1991;87:630-9.

19 Vandenplas O, Malo JL, Saetta M, Mapp CE, Fabbri LM. Occupational asthma and extrinsic alveolitis due to isocyanates: current status and perspectives. $\mathrm{Br} F$ Ind $\mathrm{Med}$ 1993;50:213-28.

20 Vandenplas O, Delwiche JP, Evrard G, Aimont P, van de Brempt X, Jamart J, et al. Prevalence of occupational asthma due to latex among hospital personnel. Am $\mathcal{F}$ Respir Crit Care Med 1995;151:54-60.
21 Cockcroft DW, Killian DN, Mellon JJA, Hargreave FE. Bronchial reactivity to inhaled histamine: a method and clinical survey. Clinical Allergy 1977;7:235-43.

22 Stenton SC, Avery AJ, Walters EH, Hendrick DJ. Statistical approaches to the identification of late asthmatic reactions. Eur Respir F 1994;7:806-12.

23 Banks DE, Sastre J, Butcher BT, Ellis E, Rando RJ, Barkman $\mathrm{HW}$, et al. Role of inhalation challenge testing in the diagnosis of isocyanate-induced asthma. Chest 1989;95 414-23.

24 Moscato G, Dellabianca A, Vinci G, Candura SM, Boss MC. Toluene diisocyanate-induced asthma: clinical findings and bronchial responsiveness studies in 113 exposed subjects with work-related respiratory symptoms. $\mathcal{F}$ Occup Med 1991;33:720-5

25 Malo JL, Ghezzo H, L'Archevêque J, Lagier F, Perrin B, Cartier A. Is the clinical history a satisfactory means of diagnosing occupational asthma? Am Rev Respir Dis 1991; 143:528-32.

26 Mapp CE, Boschetto P, Dal Vecchio L, Maestrelli P, Fabbri LM. Occupational asthma due to isocyanates. Eur Respir f 1988;1:273-9.

27 Cloutier Y, Lagier F, Cartier A, Malo JL. Validation of an exposure system to particles for the diagnosis of occupational asthma. Chest 1992;102:402-7.

28 Karol MH, Tollerud DJ, Campbell TP, Fabbri L, Maestrelli $\mathrm{P}$, Saetta M, et al. Predictive value of airways hyperresponsiveness and circulating IgE for identifying types of responses to toluene diisocyanate inhalation challenge. Am 7 Respir Crit Care Med 1994;149:611-5.

29 Durham SR, Graneek BJ, Hawkins R, Newman-Taylor AJ. The SR, Graneek BJ, Hawkins R, Newman-Taylor AJ. The temporal relationship between increases in airway induced by occupational agents. $\mathcal{F}$ Allergy Clin Immunol induced by occupati

30 Ihre E, Axelsson IGK, Zetterström $O$. Late asthmatic reactions and bronchial variability after challenge with low doses of allergen. Clin Allergy 1988;18:557-67.

31 Mapp CE Polato R Maestrelli P, Hendrick DJ, Fabbri LM. Time course of the increase in airway responsiveness associated with late asthmatic reactions to toluene diisocyanate in sensitized subjects. 7 Allergy Clin Immunol 1985;75:568-72.

32 Cartier A, Thomson NC, Frith PA, Roberts R, Hargreave FE. Allergen-induced increase in bronchial responsiveness to histamine: relationship to the late asthmatic response and change in airway caliber. $\mathcal{f}$ Allergy Clin Immunol 1982 70:170-7.

33 Thorpe JE, Steinberg D, Bernstein IL, Murlas CG. Bronchial reactivity increases soon after the immediate response in dual-responding asthmatic subjects. Chest 1987;91:215.

34 Malo JL, Ghezzo H, L'Archevêque J, Cartier A. Late asthmatic reactions to occupational sensitizing agents: frequency of changes in nonspecific bronchial responsivenes and of response to inhaled $\beta_{2}$-adrenergic agent. $\mathcal{F}$ Allergy Clin Immunol 1990;85:834-42. 